\title{
BETWEEN MARKET AND MORALITY: THE CASE OF SURROGACY Bartosz Plotka ${ }^{1}$, Cristina Iulia Ghenu ${ }^{2}$, Kamila Rezmer ${ }^{3}$
}

\begin{abstract}
In What Money Can't Buy and Justice - What's the Right Thing to Do Michael Sandel argued that nowadays we face the loss of our collective moral compass caused by the increasing role of markets in our lives. In his view, when market and moral values compete, some aspects of everyday life become corrupted. One of the author's examples is the case of surrogacy, presented as a service which corrupts parenthood. In this article we follow Sandel's argument and argue, step by step, that its logic cannot be fully applied to surrogacy and, there where it can, it is utterly wrong. That is because in fact Sandel's argumentation is not strictly economic but personalistic, as we demonstrate in the article. Our conclusion is that Sandel's personalistic approach to surrogacy cannot be generalized over all cases and cultures, and even where it is used, it is offending and discriminating against both women who want to be surrogates and the intended parents.
\end{abstract}

UDC Classification: 17, 338; DOI: http://dx.doi.org/10.12955/cbup.v6.1237

Keywords: surrogacy, market logic, economic thinking, morality, Sandel

\section{Introduction}

Our argument is that Michael Sandel's market argumentation against surrogacy in fact is personalistic and cannot be rationally defended. To illustrate this argument, we follow the author's reasoning and argue, step by step, why this kind of logic cannot be fully applied to surrogacy, and, there where it can, it is utterly wrong. Also, we present the original assumptions of personalism and show its identity with Sandel's views. To further prove the validity of our argument we present additional empirical evidence in the form of a few cases of surrogacy in which there are tendencies more general for surrogacy than Sandel's relativized reasoning and observably opposite to the author's logic. We situate our work within analytical tradition - this means that we do not focus too much on hermeneutics, but we take first, a comparative approach, then we present additional empirical cases of surrogacy and finally we demonstrate why these cases cannot be even compared with the previous ones which means by itself that they do not meet the criterion of homogeneity. The latter additionally proves that Sandel's argumentation belongs to a particular type of rationality and cannot be universalized. Our aim and result are not a holistic defense of surrogacy but defending it against at least the kind of objections represented by Sandel.

\section{Surrogacy}

Surrogacy is a service provided by women who are ready to become pregnant and give birth to a child which right after then is given to the ordering people who become the child's parents. It usually takes a form of mutual economic agreement between a surrogate and the future parents. It assumes that the woman will hand over the child right after receiving the previously agreed payment and that she will not have parenthood claims in the future. It must be noted, however, that surrogacy not always is an economic transaction. It is true that many surrogates depend on carrying pregnancies for money, but it cannot be denied that there are also altruistic ones. They happen mostly within families in which one relative carries a child for another. It is not, however, the only case of altruistic surrogacy. They happen also in the far East culture circles, especially Buddhist ones, as we illustrate in the remainder. In the case of surrogacy, it is important to understand why there is a demand for it. Söderström-Anttila et al. (2016) describe the types of situations when people decide to hire a surrogate. The first type happens when a woman is fertile but does not want to become pregnant. According to Berend (2014) the reasons of such a woman usually include the following arguments: pregnancy destroys a job career; pregnancy worsens the physical appearance; pregnancy dangers a woman's health or life. In the second type of circumstances people decide on surrogacy if a woman or a man is infertile. This further divides them into the following situations: a) an embryo is created by using a future father's sperm and a future mother's eggs, b) an embryo is created from a future father's sperm and eggs donated by other woman than the surrogate, c) an embryo is created from a future mother's eggs and

\footnotetext{
${ }^{1}$ Nicolaus Copernicus University, Faculty of Political Science and International Studies, Department of Political Theory, bplotka.umk@gmail.com,

${ }^{2}$ Bucharest University of Economic Studies, Faculty of Management, Bucharest, Romania, cristina.ghenu@man.ase.ro

${ }^{3}$ Faculty of Political Science and International Studies, Nicolaus Copernicus University, Thorn, Poland, kamila.rezmer@onet.pl
} 
donated sperm, d) an embryo is created from donated eggs and sperm and is implanted in a surrogate's womb. These scenarios have three possible genetic consequences. The child is genetically related either to both parents, to one parent or neither of them. The described scenarios usually are simplified into two kinds of surrogacy: traditional and gestational. First of them is when a surrogate is inseminated naturally or artificially. Second is when an embryo is created via in vitro fertilization and then it is implanted in a surrogate.

\section{Objections towards Surrogacy}

Surrogacy, especially gestational, is highly contentious service raising many emotionally negative reactions as well as social, economic, legal and philosophical questions varying across countries, religions and cultures. In the Christian tradition, for instance, it is treated very contemptuously and sometimes is compared to prostitution, while in fact there are little similarities between them (Sera 1997). Such a comparison shows just how many unjustified negative emotions are connected with the assessment. On the other hand, in Buddhist cultures, surrogacy is perceived as consequentially positive and bringing good to the people. As such it is commonly supported and practiced. This clash of cultural perceptions shows that the moral judgment of surrogacy depends a lot on a person's beliefs and, first of all, hierarchy and understanding of values. Bachryj-Krzywaźnia (2017) argued that every kind of social thought is based on some idea of human nature. Interestingly, in the vast majority of cases that we could name as bioethical or biopolitical, including surrogacy, the idea of human nature, whatever understood, is a primary value that influences or determines the understanding of the other ones. The intellectual consequences of these observations are as follows: a) there always is a need to identify the concept of human nature behind someone's reasoning, and b) we can predict someone's arguments if they believe in a specific concept of human nature that we know about. Following these thoughts, we present the most prevalent objections against surrogacy.

\section{Legal Objections}

The legal issues connected with surrogacy comprise the enforceability of surrogacy agreements; the legality of secondary issues involved in the surrogacy process, e.g. in vitro fertilization (IVF); the legal mechanisms of child's transition from a future or intended parent to a legal parent - namely: establishing parenthood rights; and, sometimes, e.g. in the cases of reproductive tourism, mechanisms of establishing a child's citizenship. In terms of enforceability, the major problem is a case when in the agreement there is not predicted a situation that a surrogate gives birth to an irreversibly sick child and the intended parents refuse to accept it because they wanted to have a healthy baby. On the one hand the agreement obliges them to take the child, but on the other, they do not want to do that because their intuition tells them that they are not in the exact situation that they wanted to be in. The legal problem then is a question to which concept should they refer: parental unconditional love or consumer rights? Even the bigger problem is a situation when the agreement does not predict that a surrogate mother feels so strong emotional bond with the child that she does not want to hand it over. The question then is who has parental rights? The surrogate as a partially biological mother, the ordering man as a partially biological father or the donating/ordering woman as a partially biological mother/nonbiological mother but mother according to the agreement? Giving answers to these questions is not simple. Moreover, sometimes giving them may be even more confusing than the questions itself. An example was described by Tremblay (2015) who discussed the legal status of surrogacy in Quebec where the service is completely banned and the genetic parents cannot adopt the child even if that leaves it with no legal parents. Darnovsky and Beeson (2014) report another severe problem that is caused when the intended parents decide for transnational gestational surrogacy, which means that a surrogate is a citizen of other country and the child has no genetic connection with the future parents. Despite this, they adopt the child and become its legal parents and hence there are many bureaucratic obstacles to recognize the child's citizenship. A known example are the United States which require that at least one person is the child's biological parent. Otherwise, the child is born without citizenship. The social objections towards surrogacy result particularly from the concerns about the child's citizenship. The latter concept is very broad and, according to Kymlicka (2002), has at least two basic dimensions. First is the individual connected with the liberal idea of rights and privileges, while the second refers to the communitarian idea of attachment, belonging to the group and the following responsibilities towards the society. A bioconservative communitarian would ask: if the child has biological parents from abroad and legal parents from the home country but it has no citizenship, then 
to what country does it belong and to whom are the social responsibilities due? Questions like these show what severe biopolitical challenges stand before the contemporary law, philosophy and politics, and that they must seek for new solutions mostly in the understanding of these cases rather than rejecting and excluding conservative ideas. One more legal problem that requires such an understanding is induced medically by the specificity of in vitro fertilization. According to ASRM (2014) the competition between IVF clinics causes them to implant multiple embryos to increase the birth rate. In consequence in gestational surrogacy twin and higher order pregnancies happen more often than in usual pregnancies. Now the question is who should take care of the additional child, unpredicted by the agreement? Some would answer that the situation is no different from the natural pregnancy when a woman gives birth to more than one child - then she has to accept all of them. So why should not she accept all the additional children from surrogacy? What should a legalist do? Should he recognize the analogy and adjudicate the woman must accept the additional children or should he refuse it and refer to other concepts?

Philosophical and Economic Objections

Philosophical objections towards surrogacy comprise both reflections on theoretical categories, e.g. citizenship, parenthood, human nature, human life, etc., and moral questions, e.g. is natural insemination of the surrogate by the intended father who is a husband of the intended mother right or wrong? Or is it morally justifiable to have a baby through IVF? Is surrogacy just another but natural form of pregnancy, a kind of last resort if a woman is infertile, or is it an unnecessary whim dehumanizing pregnancy by making it artificial, forced and infringing the course of nature? What are our ideas of pregnancy and why? Why shall one want to hire a surrogate while there is the possibility of adoption? Even Benatar's (2006) anti-natalist question could be asked here - why to choose having babies over not having babies?

We argue that the main line of philosophical disagreement is between bioliberals and bioconservatists. They represent two intellectual camps that disagree about the meaning of human nature and corresponding values. Bioconservatists most often base their arguments on religious beliefs or the value of community. This is why they usually support natural procreation and intuitively reject any other forms of pregnancy. Roache and Clarks (2009) therefore argue that bioconservative claims have not rational foundations and as such they should be rejected. The flagship example of such an irrational bioconservative intuition is Kass' (1997) "yuck factor" which assumes that if we find something disgusting then it cannot be good or right. But is it rational to believe that if one or more persons find something disgusting then it is bad for everyone else? Not all people like the taste of fish but does this mean that all people in the world should stop eating them? For some reason bioconservatists answer yes to these kind of questions and are ready to use the state apparatus to legally forbid actions that they find for any, usually intuitive, reason wrong. The major opponents of bioconservatists are bioliberals who advocate individuality, the concept of positive freedom and autonomy. One of their main principles is the freedom of acting as long as it does not infringe somebody else's safety or moral borders. Agnafors (2014) challenges the bioliberal convictions supporting surrogacy by referring to that principle and arguing that the service causes harm twofold. First, surrogacy cuts off the prenatal bond between a surrogate and the child. Second, harm is done because surrogacy inherently infringes maternal-fetal attachment (MFA). Interestingly, the author's argument is not supported by any scientific research or rational explanation. Moreover, he contradicts himself by arguing that interrupting the attachment process does not prevent the child's normal emotional and social functioning because of the adaptive capability and loving environment. Only his very words "attachment process" prove that even in the moment of birth the assumed bond between a surrogate and the child is not fully developed. One thing that surely is present in the author's argumentation is the intuitive conservative conviction that the biological mother and the child should not be separated.

The most important part of philosophical debate about surrogacy, however, is dominated by the bioconservative arguments based on personalism and the bioliberal defense against them. First of all, the personalist standpoint assumes that surrogacy is sinful for the same reasons for which it disdains in vitro fertilization, which is a necessary part of the gestational surrogacy. However, the reasons of the negative assessment of surrogacy by personalism are much more complex. First of these reasons is the aforementioned value of human dignity. Personalists understand it as a human being's right to be born 
worthily and claim that in the case of surrogacy that right is violated. It is because the child's kinship relations with parents are broken. Personalists claim that surrogacy causes that there is a separation of pregnancy from parenthood. Next, and simultaneously one of the major, personalist arguments concerns the character of surrogacy as a service. The proponents of this worldview claim that the substitute motherhood is treated like contract work, where following it, degradation of the child from a human being to a commodity occurs, for which there is a due amount of money. This is why more bioconservative lawyers or ethicists compare surrogacy with human trafficking. It is also because the child can be handed over to the ordering couple only after it pays the surrogate a fee for her service. Moreover, they claim that such an agreement entails much broader consequences - that it causes human relations to be economically dependent and organized. Another group of arguments concerns the dignity of woman. Personalists argue that a woman who agrees to become a surrogate is treated like an item and reduced to the role of an incubator. They also accuse the ordering couples of selecting a surrogate that meets their expectations from a group of candidates. According to personalists, it is just another manifestation of treating women like an item. Their argumentation does not end here however. They also accuse surrogates of being sheer prostitutes because they hire their bodies for a price, and for this reason they accuse the intermediary organizations of pimping (Ekman 2014). Such an analogy leads them to the conclusion that the human body, fertility, pregnancy and parenthood are reduced to the role of a commodity. According to Muszala (2009) the very same argument applies to women who decide to become surrogates for altruistic reasons. Personalism does not make any room for excuses and names an act such as auto-instrumentalization, as something that deprives the woman of autonomy, dignity and rights. Inevitably, personalism perceives surrogacy as a highly contemptuous service that depreciates parental love, parenthood, the unity of married couple, deprives the child of the chance for being truly loved and the chance for normal and healthy functioning in the society, and eventually claims that it should be banned for whatever the consequences.

\section{Michael Sandel Against Surrogacy}

In Justice - What's the Right Thing to Do Michael Sandel (2009) started the topic of hired help to demonstrate that people sometimes have intuitions that providing some services is morally wrong. One of his flagship examples is surrogacy to which he referred through the case of William and Elizabeth Stern, an infertile couple, who in 1985 hired Mary Beth Whitehead to carry a pregnancy for them in exchange for $\$ 10,000$. They signed an agreement but after giving birth to the child, Mrs. Whitehead changed her mind and wanted to keep the baby. Sterns accused her of infringing the terms of agreement and fought in court for their parental rights. Despite the judge unambiguously decided that the parental rights belong to Sterns and Whitehead has to hand the child over to them, Sandel (2009) undermines that sentence and claims it was not a typical commercial contract. In his opinion it is objectionable to buy and sell babies even if all the involved agents freely agree to do so and that the exchange between Sterns and Whitehead was a practice that turns children into commodities, and women into part of child-bearing business. The author raised two major objections towards the service. First is a doubt if Whitehead's consent was truly free. He argues that a future surrogate makes a decision under conditions of coercion caused by the lack of money and lacking full knowledge about a mother's attachment to the child. His second major objection is that surrogacy causes a devaluation of human life and parenthood because they are not valued appropriately. He bases this argument on the more general assumption that, literally: it is hard to value goods and social practices. He further developed his argument in What Money Can't Buy (2013) by claiming that "having babies in order to sell them for profit is a corruption of parenthood, because it treats children as things to be used rather than beings to be loved". The key notion here is corruption which the author understands as selling something that should never be sold.

\section{Arguments Against Michael Sandel's "Market Logic"}

Michael Sandel $(2009,2013)$ in both aforementioned books tries to convince readers that nowadays markets start to govern the sphere of life that previously were governed by norms. The market logic in his works is reduced to the combination of two values: individual freedom and social utility. When they meet, interested parties freely make a mutually beneficial agreement and exchange goods or services with each other on these pre-established terms. The problem with his reasoning starts further when he claims that whenever this logic enters into certain spheres of life, it corrupts them and causes the loss of our collective moral compass. 
We argue, on the example of surrogacy, that this argument is utterly wrong. To illustrate that we follow his arguments step by step, the author's first claim is that "it is objectionable to buy and sell babies even if all the involved agents freely agree to do so". We are surprised how many people, including famous scientists, confuse buying and selling babies with the process of carrying pregnancy. This is why we argue that there is a need to use words and definitions carefully, especially in such a delicate matter. There is a clear difference between surrogacy, which by definition, means a service of carrying a pregnancy, and human trafficking which means buying and selling people, including babies. Claiming that the former is the latter is a logical abuse. The same logic applies to the further part of Sandel's argument that "the exchange between Sterns and Whitehead was a practice that turns children into commodities". If that would be true, Sterns would not have been searching for a surrogate mother but for an already born baby on some kind of baby market. Another argument is that Whitehead's consent was not truly free because she made a decision under conditions of coercion caused by the lack of money. Lot of people need money and these people decide on different ways to earn it. The true market logic would assume that people are free to decide the way they want to earn money and that was exactly the case of Mrs. Whitehead. However, Sandel assumed for actually no reason that she was forced to take this particular job. Whatever the reason was, the author did not use market logic as he thought he did, but treated Mrs. Whitehead like having been deprived of the ability to make decisions. It was confirmed in the further part of his argument that she was lacking full knowledge about a mother's attachment to the child. It was not true, because in the moment of signing the contract Mary Beth Whitehead actually was the mother of two children. Another Sandel's argument is that surrogacy causes a devaluation of human life and parenthood because they are not valued appropriately. The thing is that no one tries to value human life and parenthood in surrogacy cases. Like in our previous counterargument, again we point out that surrogacy concerns only the pregnancy carrying process and paying a gratitude compensation for it. In surrogacy cases no one tends to buying already born children or already raised children. If that would be the case, then the argument about the devaluation of human life and parenthood would be justified. Sandel tries to defend his position by referring to a more general thought that it is hard to value goods and social practices in general. It is undeniably true, but we also think that he himself would agree that despite some difficulties, people were doing that for thousands of years. The final argument that we find completely mistaken is Sandel's conviction that "having babies in order to sell them for profit is a corruption of parenthood, because it treats children as things to be used rather than beings to be loved". First of all, it must be stressed that the argument in this form assumes that surrogates are selling their own babies, which is not true. Also, to undermine this claim we propose to reverse the presented logic and look at surrogacy as a service that underlines how strong are parental feelings and how much people are ready to do to become parents. The case of Sterns shows perfectly that they loved the child even before it was born.

We need to underline that, in the case of surrogacy, what Sandel calls market logic, in fact is nothing more than the personalistic critique of that service. There are no just accidental similarities between them, but there is substantial and almost the exact sameness. The only difference between a classic personalist and Sandel is that the second does not compare surrogacy to prostitution. Now one can ask: why do we criticize Sandel for his personalistic critique of surrogacy? We answer that market logic and personalism operate on totally different levels of rationality. The first type is based on autonomy and social utility while the second refers to the religious beliefs in some higher order that all must abide. Why do we defend the first one? Because it does not force all people to behave in the same manner, sometimes even against their will. Interestingly, Sandel (2013) made a similar observation: "too many people believe too deeply, too stridently, in their own convictions and want to impose them on everyone else" and, paradoxically, he does just that. He argues in favor of solutions which, in their simplest forms, look like "you, you and you. You will not have babies because I think that for some reasons you cannot have them. I do not exactly know these reasons, but I will not permit you to have babies anyway". However humoristic this example may be, in our opinion it reflects the cruel and coercive nature of personalists' arguments. The same cruel nature is present in the claims that a woman who freely and voluntarily decides to become a surrogate is treated like an incubator and loses dignity. Personalists do not discern that there are also other meanings of dignity that people can believe in. The example is Hughes" (2009) proposition who defined it as "the ability of individuals to achieve a sense of their unique worth and pursue their vision of the good life". According to this definition the surrogate as well as the intended parents achieve even more dignity than they had before 
because they realize their image of good life. This is not however, a personalist's vision of good life and as different, it is despised to this extent that he is ready to offend these people by calling them as the prostitute and panders, while there is no rational justification for it as Sera (1997) analytically proved in her study. Ultimately we argue that the personalistic critique of surrogacy has no rational basis and as such it cannot be maintained as a rational worldview and, moreover, we argue that the true market logic, however imperfect, helps people to pursue their most desired goals and organizes, rather than corrupts, social relations and keeps them in order. But to further prove the right of our argumentation, we refer to additional empirical evidence. Whittaker (2014) conducted a qualitative study in which she analyzed reasons of Thai women to become surrogates. Especially one of them draws the attention: "My reasons are two. First, I'd like to pay off both the loans for my university studies and for my motorbike. I'd like to send some money to my family who live in the province to fix our house and to help my mom who gave me life. Second, my Buddha teach about is good karma to help someone have life. I would be very happy if I can help someone want to have the baby dream come true. I am lucky I am strong body and have a good heart. If I can carry baby for someone want a lot, I can make many people happy to.... When we go to temple, many monks tell us this good idea because is wonderful if we can help to give someone life. I am happy, healthy and strong. I want to share my good luck about this". Surrogacy in the worldview of this Thai woman (but also in Buddhist tradition) is not only a service that helps people to achieve their individual desires, but it increases the general amount of good and happiness in the world. Such a perception cannot be even compared with the previous, personalistic, argumentation because it completely represents a different idea of human life and the aspect of altruism. In the previous cases altruistic surrogacy was understood as carrying pregnancies within families by one relative for another. It increased something that we could name as the local utility. In far East cultures, altruistic surrogacies happen according with the logic of consequentialism: to minimize harm and maximize good among people. Such an observation additionally strengthens our argumentation that the logic of personalism cannot be globally applied because it maximizes the harm of people who want to have a baby but for whatever reason, they cannot to fulfill their dream.

\section{Conclusion}

In this article we presented what surrogacy is, what are the major objections towards it, with emphasis on the personalistic critique, and compared the latter with the argumentation of Michael Sandel. In result of our approach we demonstrate that in case of surrogacy there is only one difference between the author and personalists: he does not compare surrogacy to prostitution, which, even if he would, could not be rationally maintained. Our greatest achievement however is to prove that the personalist approach to surrogacy cannot be universalized and generalized over all cases and cultures, and even where it is used, it is offending and discriminating against both women who want to be surrogates and the intended parents.

\section{References}

ASRM (American Society for Reproductive Medicine) (2012). Multiple Pregnancy and Birth: Twins, Triplets, and Highorder Multiples. Retrieved from http://www.asrm.org/BOOKLET_Multiple_Pregnancy_and_Birth/.

Bachryj-Krzywaźnia, M. (2017). Antropodoksa polityczna jako kategoria teoretyczna i przedmiot badań. Wrocławskie Studia Politologiczne, 23, 21-40.

Benatar, D. (2006). Better Never to Have Been The Harm of Coming into Existence. Oxford: Clarendon Press.

Berend, Z. (2014). The Social Context for Surrogates' Motivations and Satisfaction. Reproductive BioMedicine Online, i(4), 399-401.

Darnovsky, M., Beeson, D. (2014). Global Surrogacy Practices. International Forum on Intercountry Adoption and Global Surrogacy, 11-13 August 2014, The Hague, Netherlands.

Ekman, K. (2014). Being and Being Bought: Prostitution, Surrogacy and the Split Self. Melbourne: Spinifex Press.

Hughes, J. (2009). TechnoProgressive Biopolitics and Human Enhancement. In Progress in Bioethics, J. Moreno, S. Berger (Ed.). MIT Press, 163-188.

Kass, L. (1997). The Wisdom of Repugnance. The New Republic, 2, 17-26.

Kymlicka, W. (2002). Contemporary Political Philosophy: An Introduction. New York: Oxford University Press.

Roache, R., Clarks S. (2009). Bioconservatism, Bioliberalism, and the Wisdom of Reflecting on Repugnance. Monash Bioethics Review, 28(1), 4.1-4.21.

Sandel, M. (2009). Justice. What's The Right Thing To Do? New York: Farrar, Straus and Giroux Press. 
Sandel, M. (2013). What Money Can't Buy. The Moral Limits of Markets. London: Penguin Books.

Sera, J. M. (1997). Surrogacy and Prostitution: A Comparative Analysis. Journal of Gender \& the Law, 5(2), 315-342.

Söderström-Anttila, V., Wennerholm, U. B., Loft, A., Pinborg, A., Aittomäki, K., Romundstad, L. B., Bergh, C. (2016).

Surrogacy: outcomes for surrogate mothers, children and the resulting families-a systematic review. Human Reproduction Update, 22(2), 260-276.

Tremblay, R. (2015). Surrogates in Quebec: The Good, the Bad and the Foreigner. CJWL, 27(1), 94-111.

Whittaker, A. (2014). Merit and Money: The Situated Ethics of Transnational Commercial Surrogacy in Thailand. The International Journal of Feminist Approaches to Bioethics, 7(2), 100-120.

goldwaterdube.com. (2018). Why is Surrogacy Illegal in Quebec? Retrieved from

http://www.goldwaterdube.com/blog/5059/surrogacy-illegal-quebec.html 